\title{
Intragastric Balloon Left in the Stomach for More than a Year: Two Case Reports
}

\author{
Athanasios D. Sioulas Dimitrios Polymeros Anastasia Kourikou \\ Ioannis S. Papanikolaou Konstantinos Triantafyllou \\ Hepatogastroenterology Unit, 2nd Department of Internal Medicine-Propaedeutic, Attikon \\ University General Hospital, Medical School, University of Athens, Haidari, Greece
}

\author{
Key Words \\ Obesity $\cdot$ Obesity management $\cdot$ Weight loss $\cdot$ Intragastric balloon
}

\section{Abstract}

Objective: Intragastric balloon (IGB) is often used to achieve short-term weight reduction in morbidly obese patients. It is placed endoscopically for a 6-month-period either in the prebariatric surgery setting and also in cases where no bariatric surgery is planned. Prolonged implantation may be accompanied by serious complications. Case Reports: We herein report two cases of extraction of intact IGBs long time after their placement. Conclusion: Although no adverse events were observed, adherence to manufacturers' recommendations is definitely suggested.

\section{Introduction}

Many conventional approaches have been applied to reduce excessive weight and its consequences in obese individuals, such as dietary change, exercise, medications, and behavioral modification. All these modalities are usually used for a long time with only moderate results [1].

Bariatric surgery is the most effective weight loss method available to provide longterm, sustained outcomes. However, surgical procedures are invasive and burdened with numerous, even fatal complications [2]. 
Sioulas et al.: Intragastric Balloon Left in the Stomach for More than a Year: Two Case Reports

Fig. 1. The deflated balloon grasped through the endoscope after its removal.

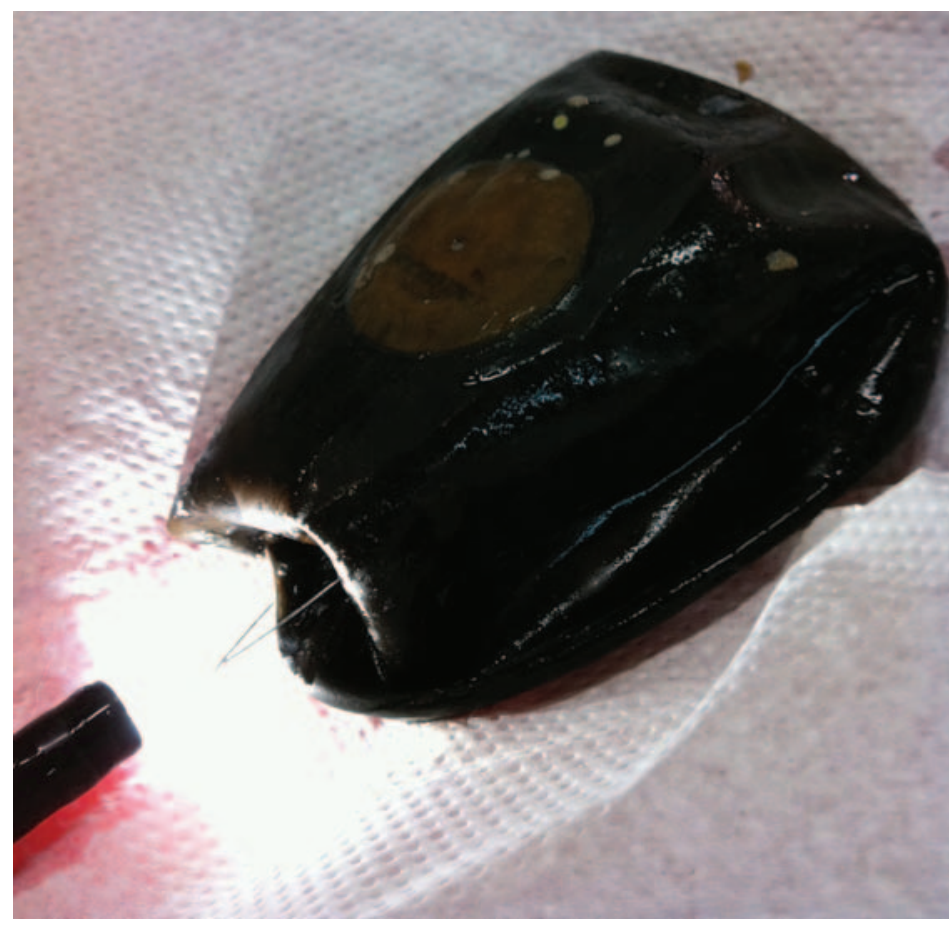

Endoscopic placement of an intragastric balloon (IGB) is a minimally invasive technique proposed to induce short-term weight reduction. It is used for a 6-month-period in morbidly obese patients either in the pre-bariatric surgery setting and also in cases where no bariatric surgery is planned $[3,4]$.

We herein report two cases of IGB removal long time after their placement.

\section{Case Reports}

Case 1

A 45-year-old man presented to our Endoscopy Unit for IGB removal 2 years after its placement, according to our records. He was an obese individual with a BMI of $35 \mathrm{~kg} / \mathrm{m}^{2}$ and a body weight (BW) of $115 \mathrm{~kg}$. His medical history was significant for dilated cardiomyopathy, coronary artery disease, congestive heart failure, restrictive lung disease, diabetes mellitus, chronic renal failure, and hypothyroidism. He reported multiple hospitalizations during the last 2 years for acute myocardial infarction and pulmonary edema episodes that prevented balloon removal on the appropriate time. He claimed that he had lost $15 \%$ of his BW during the first 6 months, but gradually regained it afterwards.

An esophagogastroscopy was performed and a full-filled, greenish balloon appeared inside the stomach. A needle catheter was then passed through the scope, the balloon was punctured and about 600 $\mathrm{ml}$ of fluid (saline and methylene blue) were suctioned until complete balloon deflation. Eventually, the balloon was grasped with forceps and carefully retrieved (fig. 1). It was a BioEnterics Intragastric Balloon ${ }^{\circledR}$ (BIB) (Inamed Health, Santa Barbara, CA, USA). Mild erythema of the gastric body and antrum was observed after balloon's extraction. The procedure was accomplished with deep sedation under anesthetist's supervision.

Case 2

A 55-year-old man presented to our Endoscopy Unit for IGB removal. According to his records, an airfilled Heliosphere Bag ${ }^{\circledR}$ Intragastric Balloon (HIB) (Helioscopie, Vienne, France) had been introduced in 
Sioulas et al.: Intragastric Balloon Left in the Stomach for More than a Year: Two Case Reports

Fig. 2. An intact balloon just below the gastroesophageal junction.

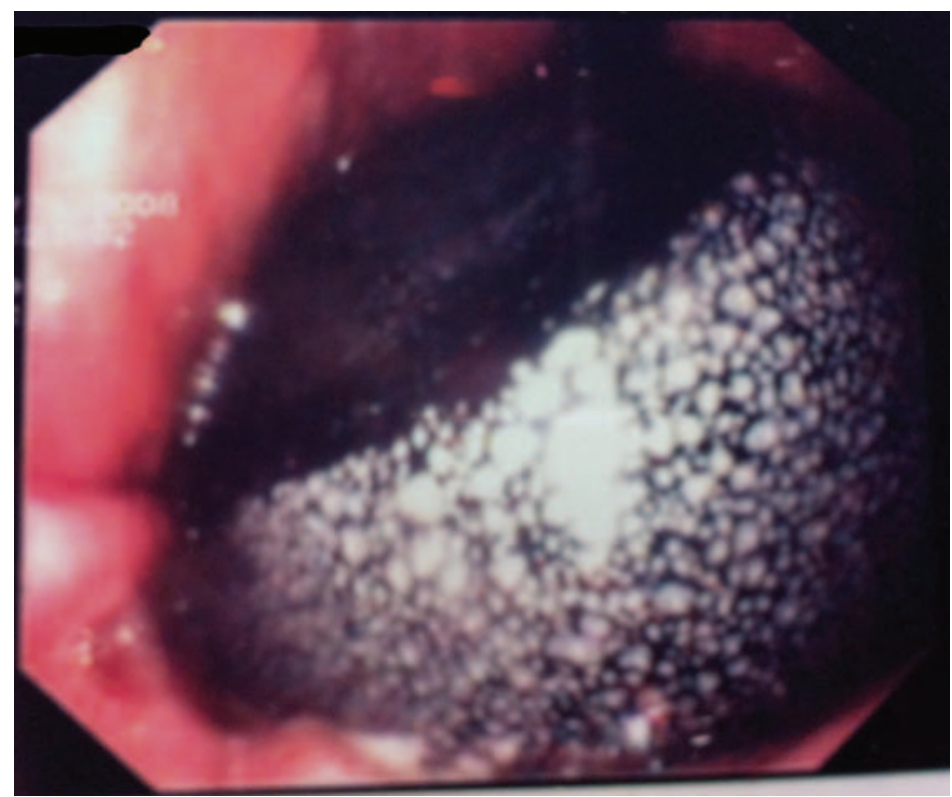

his stomach 13 months ago elsewhere. He admitted to have postponed doing so after the first 6-month period, since his job as a cruise ship captain left him no free time. On physical examination, he was overweight with a BMI of $27 \mathrm{~kg} / \mathrm{m}^{2}$ and a BW of $97 \mathrm{~kg}$. He did not notice any weight loss, despite his adherence to diet. His medical history was noncontributory.

An esophagogastroscopy was carried out under deep sedation provided by an anesthetist, and the air-filled black-green colored balloon appeared intact in its position in the stomach (fig. 2). Thereafter, the balloon was punctured with a needle catheter, completely deflated after air aspiration and finally extracted using a grasper. No mucosal abnormalities were noted following balloon removal.

\section{Discussion}

To our knowledge, these are the first two cases in the literature describing intact IGB extraction after such an extended period of time. To date, maximum duration of IGB treatment reaches 1 year [5].

IGB is placed endoscopically to achieve moderate weight loss as part of the multidisciplinary management of obesity. Currently, two types of balloons are available; the air-filled and the saline-filled. Both of them are placed and removed similarly and for both it is recommended that the IGBs should not remain in the stomach for more than 6 months. Beyond this period the acidic gastric content weakens the balloon material and may cause its spontaneous, complete or partial deflation. Subsequently, the balloon may migrate through the pylorus into the small bowel and lead to intestinal obstruction, especially in patients who have had previous abdominal surgery. This condition requires urgent laparotomy and surgical balloon removal [6].

Spontaneous deflation of the IGB has been reported in earlier series to occur in 1.6-6.3\% of patients with HIB and in 2-23\% of those with BIB [7, 8]. However, in a recent study with 82 consecutive obese patients treated with HIB, two spontaneous deflations occurred (3\%), but only one surgical removal (1.2\%) was required [9].

In a double-blind study comparing the two balloons, it was shown that, while all 15 BIB were removed easily and uneventfully, 2 HIB were not found in the stomach and 4 patients 
required either rigid esophagoscopy or surgery for balloon extraction, indicating that there are technical issues with the air-filled balloon [10].

To note, in a report assessing safety, tolerance, and efficacy of 1-year BIB treatment, the rate for spontaneous deflation was $2 \%$ [5].

In conclusion, although we herein report the safe removal of two IGBs (HIB and BIB) long after their placement, we still suggest strict adherence to manufacturers' recommendations in order to avoid severe complications.

\section{Disclosure Statement}

No conflicts of interest to declare.

\section{References}

1 Douketis JD, Macie C, Thabane L, Williamson DF: Systematic review of long-term weight loss studies in obese adults: clinical significance and applicability to clinical practice. Int J Obes 2005;29:1153.

2 Buchwald H, Avidor Y, Braunwald E, Jensen MD, Pories W, Fahrbach K, Schoelles K: Bariatric surgery: a systematic review and meta-analysis. JAMA 2004;292:1724-1737.

3 Imaz I, Martínez-Cervell C, García-Alvarez EE, Sendra-Gutierrez JM, Gonzalez-Enriquez J: Safety and effectiveness of the intragastric balloon for obesity. A meta-analysis. Obes Surg 2008;18:841-846.

4 Gottig S, Weiner RA, Daskalakis M: Preoperative weight reduction using the intragastric balloon. Obes Facts 2009;2:20-23.

- 5 Mathus-Vliegen EM, Tytgut GN: Intragastric balloon for treatment-resistant obesity: safety, tolerance and efficacy of 1-year balloon treatment followed by a 1-year balloon-free follow-up. Gastrointest Endosc 2005; 61:19-27.

6 Zdichavsky M, Beckert S, Kueper M, Kramer M, Konigsrainer A: Mechanical ileus induces surgical intervention due to gastric balloon: a case report and review of the literature. Obes Surg 2010;20:1743-1746.

7 Mion F, Gincul R, Roman S, Beorchia S, Hedelius F, Claudel N, Bory RM, Malvoisin E, Trepo F, Napoleon B: Tolerance and efficacy of an air-filled balloon in non-morbidly obese patients: results of a prospective multicentre study. Obes Surg 2007;17:764-769.

8 Dumonceau JM: Evidence-based review of the Bioenterics intragastric balloon for weight loss. Obes Surg 2008;18:1611-1617.

9 Lecumberri E, Krekshi W, Matia P, Hermida C, de la Torre NG, Cabrerizo L, Rubio MA: Effectiveness and safety of air-filled balloon Heliosphere BAGB $^{\circledR}$ in 82 consecutive obese patients. Obes Surg 2011;21:15081512.

10 De Castro ML, Morales MJ, Del Campo V, Pineda JR, Pena E, Sierra JM, Arbones MJ, Prada IR: Efficacy, safety and tolerance of two types of intragastric balloons placed in obese subjects: a double-blind comparative study. Obes Surg 2010;20:1642-1646. 